\title{
Effect of produced sand particles and fines on scale inhibitor: a review.
}

\author{
ANYANWU, U.C. and OLUYEMI, G.F.
}

2021

Copyright: (C) 2021 by the authors. Licensee MDPI, Basel, Switzerland. This article is an open access article distributed under the terms and conditions of the Creative Commons Attribution (CC BY) license (https://creativecommons.org/licenses/by/4.0/). 


\title{
Effect of Produced Sand Particles and Fines on Scale Inhibitor: A Review
}

\author{
Uche C. Anyanwu * and Gbenga F. Oluyemi
}

School of Engineering, Robert Gordon University, Aberdeen AB10 7GJ, UK; g.f.oluyemi@rgu.ac.uk

* Correspondence: u.c.anyanwu@rgu.ac.uk

\begin{abstract}
Application of scale inhibitors in oil and gas production is aimed at mitigating scale blockage during production. Many experimental, mathematical, and numerical simulation modeling works have been carried out to evaluate behavior, performance, and interaction of the scale inhibitor chemicals within porous media in relation to their efficiency in solving scale problem. However, the mechanisms underpinning scale inhibitors performance are not well published. Some research works have shown theoretically that not all scale inhibitors pumped into the formation adsorb onto the formation rock. Some of the inhibitors may adsorb on produced loose sand grains or colloidal fine sand particles which float and flow within the pore spaces along with the scale inhibitor mostly in unconsolidated reservoirs This paper provides a review of research work on the effect of produced loose sand or colloidal fine particles flow on polyphosphonates and polyphosphinopolymer scale inhibitors performances during crude production.
\end{abstract}

Keywords: adsorption; scale inhibitors; fine sands; colloids; reservoir

check for

updates

Citation: Anyanwu, U.C.; Oluyemi, G.F. Effect of Produced Sand Particles and Fines on Scale Inhibitor: A

Review. Colloids Interfaces 2021, 5, 35. https://doi.org/10.3390/

colloids5030035

Academic Editor: Huan J. Keh

Received: 4 May 2021

Accepted: 18 June 2021

Published: 23 June 2021

Publisher's Note: MDPI stays neutral with regard to jurisdictional claims in published maps and institutional affiliations.

Copyright: (c) 2021 by the authors. Licensee MDPI, Basel, Switzerland. This article is an open access article distributed under the terms and conditions of the Creative Commons Attribution (CC BY) license (https:// creativecommons.org/licenses/by/ $4.0 /)$.

\section{Introduction}

The mechanism underpinning sand particles and fines interactions with scale inhibitor performance is difficult to understand. Sand production from unconsolidated formation reservoir is a very challenging problem as it ends the production life of a reservoir, and as well restricts the production flow rate [1].

Sand production occurs when the stress on the formation exceeds the formation strength and results in rock failure due to tectonic activities, overburden pressure, increase in the production rate of reservoir fluid due to a large pressure drawdown between the reservoir pressure and wellbore flowing pressure, stress induced during drilling, and also producing fluid drag force [2].

In addition, the acidizing process reduces the compressive strength of the formation rock to weaken the consolidated formation for sand fines production to occur $[3,4]$. Selecting an appropriate technique for preventing formation sand production depends on different reservoir parameters, such as the sand prediction technique [1]. Others are resin and hydrogel chemical injection [5].

Furthermore, injection of surface active media such as chemical surfactants aimed at lowering surface energy (interfacial tension; IFT or surface tension; SFT) may affect the mechanical behavior of porous media by weakening the reservoir fabric, thereby causing loose sand fines occurrence through adsorption phenomenon [6,7].

Although this is dependent on the reservoir geology during the sedimentation process and type of injected surface-active chemicals surfactants, loose rock fine grains can affect reservoir rock permeability performance. Prempeh et al. [8] examined the effect of aqueous salinity water with different ionic strengths and fresh water on fines migration in the laboratory using sand-packs that contain different percentage of kaolinite and residual oil. They suggested that loose natural reservoir kaolinite fines can occur under decreasing water salinity, and their migration and retention within the porous media affect rock permeability. This revealed that low salinity water injection could promote disintegration of rock fabrics, 
fine grains formation, and scale deposition. Injection of seawater into oilfield reservoirs to maintain reservoir pressure and improve secondary recovery is a well-established oil and gas recovery technique in mature field, but one of the risks associated with such technology is deposition of mineral scales due to reactions of two incompatible waters [9].

According to Merdhah and Yassin [9], two incompressible solution waters containing dissolved materials with higher concentrations than their equilibrium concentration, such as seawater, with high concentration of polyatomic anion sulfate $\left(\mathrm{SO}_{4}{ }^{-2}\right)$ and formation waters with high concentrations of calcium ion $\left(\mathrm{Ca}^{+2}\right)$, barium ion $\left(\mathrm{Ba}^{+2}\right)$, and strontium ion $\left(\mathrm{Sr}^{+2}\right)$ will assume supersaturation condition and form scale blockage. They also reported that supersaturation can be generated in a single water by changing the temperature and pressure (T-P) conditions.

This shows that concentrations of injected water and reservoir water with different ionic reactions and T-P variation are critical to scale formation scenario. Hasson et al. [10], in this regard, identified water containing ions of sparingly soluble salts such as $\mathrm{CaCO}_{3}$, $\mathrm{CaSO}_{4}, \mathrm{Ca}_{3}\left(\mathrm{PO}_{4}\right)_{2}, \mathrm{Mg}(\mathrm{OH})_{2}$, and silica as responsible ions for scale deposition. Scale could plug the pores of the formation and results in injectivity decline of fluids into the reservoir with time [11].

Nevertheless, scale inhibitors are one of the recent technologies used to mitigate waterinsoluble scale during oil and gas production [12-17]. Scale inhibitors are chemicals which delay, reduce, or prevent scale formation when added in small amounts to normally scaling water [9]. Bezemer and Bauer [18] listed common classes of inhibitor chemicals as inorganic phosphates, organophosphorus compounds, and organic polymers, which include polyphosphonocarboxylic acid (PCA) and diethylenetriaminepenta (methylenephosphonic acid) (ETPMP). Hydrochloric acid ( $\mathrm{HCl}$ ) may be the most cost-effective treatment to remove calcium carbonate, but corrosion control, system compatibility, and inhibitor adsorption may all be difficult in a combined treatment [9].

Many experimental, mathematical, and numerical simulation modeling works [19-21] have been carried out to evaluate behavior, performance, and interaction of the scale inhibitor chemicals within porous media in relation to their efficiency in solving scale formation problems. These studies have focused only on the evaluation behavior, performance, and interaction of scale inhibitor chemicals in relation to scales mitigation efficiency within porous media. Squeeze treatment designed for steady injection of inhibitor is also published [22].

The success of a squeeze treatment is determined by the length of time in which inhibitor is released back into the produced fluid at minimum inhibitor concentrations (MIC) and this time is dictated by the retention/release mechanism of inhibitor in the reservoir $[23,24]$. In adsorption squeeze treatments, the amount of inhibitor adsorbed, and the lifetimes are dependent on the properties and surface chemistry of the reservoir system [15].

Squeeze treatment is governed by adsorption, desorption, precipitation, and dissolution (Phase separation) interactions between the scale inhibitor and formation rock [25]. Adsorption phenomenon can be best described using adsorption isotherm $r(c)$ and may be a function of several variables such as concentration of inhibitor [c], calcium concentration $\left[\mathrm{Ca}^{2+}\right], \mathrm{pH}$, and temperature [26]. Adsorption of scale inhibitor is thought to occur through electrostatic and Vander Waals interaction between the inhibitor and formation minerals [27]. In carbonate formation where the unconventional squeeze treatment method is used, the majority of the acid phosphonate inhibitor is precipitated near the formation face. The formation of Ca-phosphonate resulting from the reaction of acid with carbonate in the formation proceeds very rapidly and this has a shortcoming in a carbonate formation [28]. The unprecipitated inhibitors occurring during these unsuccessful treatments are quickly swept from the formation because they are not retained [23], the result of this being shorter treatment lifetimes and inefficient use of inhibitor, demand for subsequent treatments, lost production time, and significant cost. 
However, the mechanism of inhibitor-sand interaction and their performance in sand producing reservoir is not well published, and it is difficult to understand. This represent a gap in knowledge which can be addressed by using experimental and numerical methods. The experimental method may involve the use of engineered sand pack flooding investigation process with polyphosphonate and polyphosphinopolymer scale inhibitors, and lab-based brine and low salinity aqueous water, and validation of lab results with the numerical method.

\section{Fine Sand Production in Formations}

Fine sand production in oil and gas wells has been an issue of concern (Figure 1) because it has caused operational and economic problems in the oil and gas industry. The main issues in respect to fine sand production are the potential risk of well failure, limited productivity, erosion of facilities, and increased operational expense [29]. Figure 1 shows the production separator that was shut down because of ingress of formation fine sands.

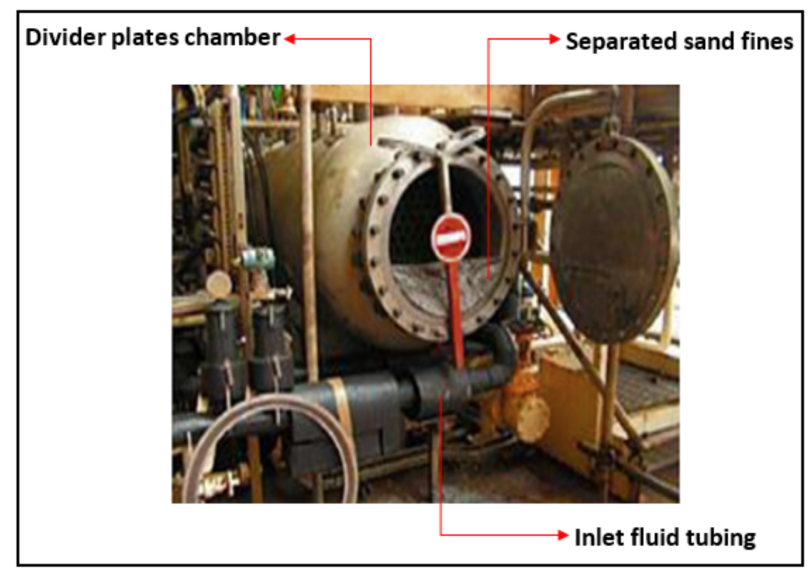

Figure 1. Illustration of separated sand fines from the produced hydrocarbon within a two-phase horizontal separator. Extracted and modified after [29].

Fine sand production is currently a subject of extensive study in the oil and gas industry. The study of sand production has focused on prediction of failure of sand and subsequent production, estimation of produced sand volume and rate, and measures for controlling or removing sand in the well [30]. Studies to evaluate the effect of fine sand on corrosion inhibitor activity using rotating cylinder flow (RCF) and flow loop for comparison have shown that the inhibitor was capable of adsorbing on sand thereby canceling out its activity [31].

However, virtually little or no knowledge exists on how fine sand production affects the effectiveness of common types of scale inhibitors used in the sand-producing reservoirs for flow assurance purposes. Figure 2 shows the arrangement of reservoir outcrop with very much sorted (A) with no amounts of loose clay/fine sand particles within the formation pores, and a very poorly sorted outcrop (B) with significant amounts of loose clay/fine sand particles within the formation pores. 


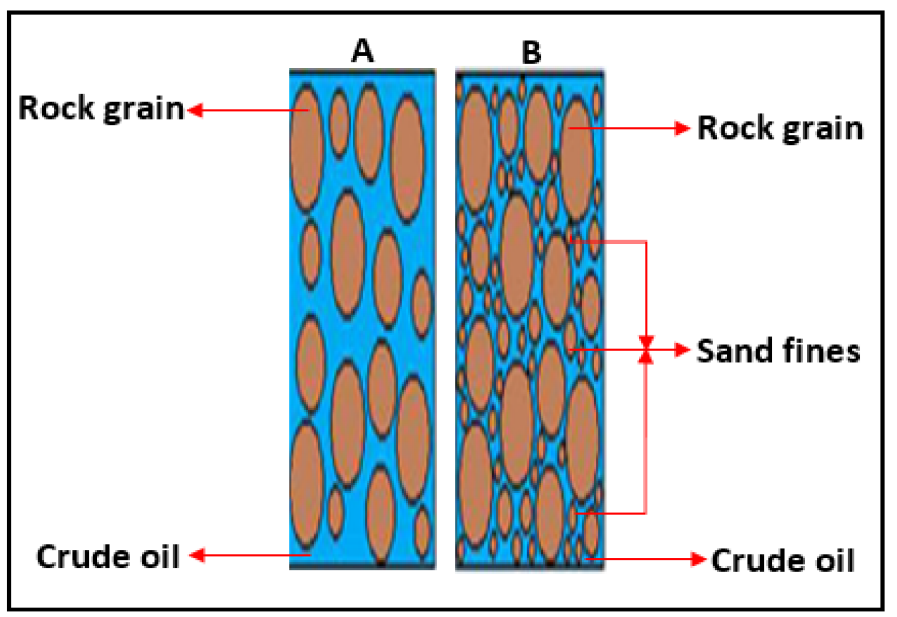

Figure 2. Pore arrangement of a very well sorted reservoir (A) with no clay/fine sand contents and a very poorly sorted reservoir (B) with much clay/fine sand contents. Modified after [32].

The effective performance of chemical inhibitors in rock sample B is not well known and has not been well reported. The in-depth understanding of loose sand fines effect on chemical inhibitors can be used to design and optimize scale inhibitor squeeze applications especially in reservoirs or wells with the potential to produce sand.

\subsection{Migration of Colloidal Fines}

Several physical and chemical processes accompany the squeezing and adsorption of scale inhibitors onto formations, thereby affecting their desired performance. The migrations of colloidal particles, which are present in natural rock porous media and unconsolidated porous media such as packed beds, is considered to facilitate or hinder the mobility of other colloids in porous media [33]. It has been reported that the existence of mobile colloidal fines under certain conditions can serve as adsorbents and potentially relevant transport mechanism for materials [34]. The detachment of an adsorbed particle results from a balance between external forces exerted on it. These forces are adhesion or physicochemical interactions, drag and lift forces. Furthermore, physicochemical interactions between particles or a particle and grain surface include Van der Waals and electrical double layer forces [35]. This physicochemical interaction could also account for the continued adsorption of the solute on loose sand particles. However, it has been reported that particle release is caused by electrostatic repulsion which is enhanced by low ionic strength and not flow-induced shear forces [36]. Solutes such as polymers, surfactants, and resins adsorbed on the particle surface affects the colloidal suspension stability by increasing steric interaction in nonporous media with tendencies to alter apparent surface charge on colloidal particles [37].

Fielder [38] carried out scale inhibitor product performance qualification screening using the seeded static jar test and continuous stirring, whereby suspended solids such as calcite and kaolinite were applied. Fielder suggested that the poor performance of the tested inhibitors may be partially caused by the presence of the suspended solids and or old scale deposits. However, his experimental work on suspended solids did not involve continuous flow or flood test backed up by simulation and moreover, it was not clear whether suspended solids or old scale deposits were the cause of poor performance of the tested scale inhibitor.

Chakraborty et al. [39] examined the effects of loose grain silica gel grain size and layers on adsorption chiller. They concluded that the use of various loose grain silica gel designs in the sorption bed allows for significant effects on the coefficient of performance and cooling capacity of adsorption chiller. Conversely, they maintained that the coefficient of performance of the chiller was affected by heat capacity, inert mass, heat losses and heat exchanger because of loose silica gel grains. The dissolution of grain fabrics 
from rock-chemical interactions increased the porosity and permeability of the sandstone formation [40]. The dissolved grain fabrics could affect the adsorption and desorption performance of squeezed chemical inhibitor because loose sand grains from the dissolved grain fabric could potentially be adsorbents for scale inhibitors. This rock-chemical interaction was attributed to Van der Waal forces which bind the chemical to the rock surfaces [35] through adsorption.

This review has been carried out to examine journal reports on adsorption and desorption behavior of the most commonly used oil and gas scale inhibitors and how production of colloidal fine sands in reservoirs affect the performance of scale inhibitors in sandproducing reservoirs.

\subsubsection{Scale Inhibitors}

Scale inhibitors used in squeeze treatment provide one of the most common and efficient methods for preventing the formation of scales in producer wells. The selection of these scale inhibitors is geared towards the accomplishment of the following tasks [41]:

To prevent or delay the formation of scales (either sulphate or carbonate scales) at very low concentrations otherwise known as the minimum inhibitor concentration (MIC) or threshold concentration $\left(\mathrm{C}_{\mathrm{t}}\right)$;

To interact with the reservoir or formation substrates in order to give high adsorption over a short period of shut-in time;

To interact, to a large extent, with the reservoir or formation materials to give long inhibitor desorption or return profile at or above MIC or $C_{t}$ level.

Additionally, it is not sufficient that scale inhibitors interact appropriately with the formation or adsorbent [24], but that they also be compatible with brine composition and comparably stable to thermal degradation. Non-compatibility of scale inhibitors and the brine system might likely result in the precipitation of the inhibitor prior to injection or at the near well bore areas, thereby resulting in the formation of makeshift fine scales which might cause the plugging of formation pores. Furthermore, the scale inhibitors selected must be such that they are not degraded or dissociated in the course of the operation due to the formation temperature and sometimes change in formation temperature.

Scale inhibitors are considered to have very marked effects on the growth rate of crystals deposited in a scaling environment. These threshold inhibitors function by adsorbing onto the growing crystals and distorting the lattice, which disrupts the crystal growth process [14]. Interaction between the polyaspartic acid (PASP) scale inhibitor with calcite crystal surface is mainly because of the strong $\Lambda-\Lambda$ interaction between the $\Pi^{4}{ }_{3}$ delocalized bonds of $-\mathrm{COOH}$ groups in PASP and $\Pi^{6}{ }_{4}$ delocalized bonds on the surface of calcite crystal, and the hydrogen interactions between them and water molecules. Further reported is that polymer inhibitors do not interact directly with calcite crystal in the water solution, but indirectly through the chemical bonds and non-bond interactions between PASP and $\mathrm{H}_{2} \mathrm{O}$ and calcite [42].

Several classifications and types of scale inhibitors have been reported [43]. Among these classifications, polyphosphonates and polyphosphino polymers have been profusely and widely employed in oil and gas scale control due to their high scale inhibition efficiency, low economical cost, and relative environmental compatibility.

Jordan et al. [12] reported that phosphonates at elevated temperatures, particularly from $70{ }^{\circ} \mathrm{C}$, perform very well. Additionally, they added that at and above $70{ }^{\circ} \mathrm{C}$, the phosphonates exhibit strong retention characteristics and excellent release profiles which make them the choice chemical for scale squeeze treatment, though low temperature does not favor retention of their molecules on the rock rather the phosphonate ester chemicals. In contrast, studies have indicated that phosphonates generally adsorbed poorly onto sandstone with squeeze lifetimes often unsatisfactory [15]. However, it has been ascertained that the presence of phosphorus in the monomer building block of phosphonates was incorporated to provide good retention properties and relative ease of detection [27,44] Ketrane et al. [45] in their study have compared the efficiency of five scale 
inhibitors, three polyphosphates, one polyphosphonate, and one polycarboxylic acid, and claimed to have observed that phosphonates are better inhibitors than polycarboxylates or polyphosphates. This could be attributed to their characteristic mono- or multi-functional groups $\left(-\mathrm{PO}_{3} \mathrm{H}_{2}\right)$ that contain short chains and kinetically more stable bonds $\mathrm{P}-\mathrm{C}-\mathrm{P}$ or $\mathrm{P}-\mathrm{C}-\mathrm{N}-\mathrm{C}-\mathrm{P}$ than P-O-P bonds of condensed phosphates and the P-O-C ester linkage which are sensitive to hydrolysis and susceptible to oxidation and reduction $[45,46]$.

Several importance of the use of phosphonate inhibitors in the field with reference to aminotri (methylene phosphonic acid) (ATMP) have been highlighted [23] to include:

The economic viability of the scale inhibitors which stem from their ability to inhibit the scale at low concentration;

Their stability over a wide range of temperature and $\mathrm{pH}$;

Their versatility of use as scale inhibitors to mitigate diverse forms of scale;

The relative ease with which their concentration in the produced fluid can be determined, thereby providing information on retreatment time for the well.

The essentiality of phosphorus as a nutrient for the growth of aquatic algae and other biological organisms has been elucidated. However, further reported is that excessive use of phosphonates would introduce uncontrolled phosphorus into the natural water bodies such as lakes and reservoirs with resultant algae blooms and eventual degeneration of water quality [47].

Many chemicals such as organic phosphonates, organic phosphates, and low molecular weight ester derivatives of these molecules with desired secondary properties have been widely used as scale inhibitors in oil and gas applications [48]. Nevertheless, ongoing efforts are geared towards green scale inhibitors such as polycarboxylic acids and polyacrylates and their copolymers, which are eco-friendly [41]. The need for replacement presumably stemmed from their corrosive and bacterial fouling characteristics which necessitates their application in a mixture of other additives. At high concentrations of these chemicals, they become too acidic and affect seaweed and constitute environmental concerns, as a result, they have become increasingly restricted for use [49]. Structural representation of different organo-phosphonate scale inhibitors with different functional groups and a carboxylic acid inhibitor most commonly used as scale inhibitors are depicted in Figure 3 below.

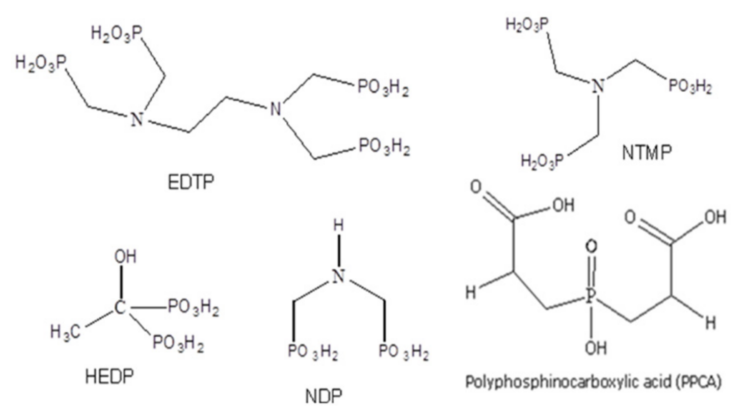

Figure 3. Molecular structures of some organo-phosphonate-based inhibitors (adapted from [50]).

The number of phosphonate, carboxylic, and hydroxyl groups attached to a compound has a significant role in the inhibition efficiency of the molecule. The phosphonate groups strongly adsorb onto the $\mathrm{BaSO}_{4}$ or $\mathrm{CaCO}_{3}$ crystalline substrate owing to the high chelating ability of the $-\mathrm{P}(\mathrm{O})(\mathrm{OH})_{2}$ groups when ionized to $\mathrm{PO}_{3}{ }^{2-}$ [51]. However, polyphosphinocarboxylic acid (PPCA) has been reported to lower the ionic activity product of scales through either chelating of the metal ions or by decreasing $\mathrm{pH}$ [49]. Polyphosphinocarbolylic acid is characterized by its reactive carboxylic and hydroxyl functional groups, which makes it an effective scale inhibitor and gives it a wide application in oil and gas systems. However, phosphonate molecules are characterized by their multiple functional groups with varying charges which depend on $\mathrm{pH}$ as well as in their interactions with available cations [50]. 
Hao et al. [52], in their study on the preparation and adsorption performance of aqueous glyphosate on manganese oxide-powdered activated carbon $\left(\mathrm{MnO}_{2} / \mathrm{PAC}\right)$ composite, have reported that the uptake rate and the kinetics of adsorption are essential parameters to consider in designing appropriate adsorption isotherm because they determine the residence time of adsorbed solute. Figure 4 below shows kinetic adsorption of glyphosate solute on porous $\mathrm{MnO}_{2}$ /PAC-packed bed, which in general, elucidates kinetic adsorption pathways for most of the scale inhibitors.

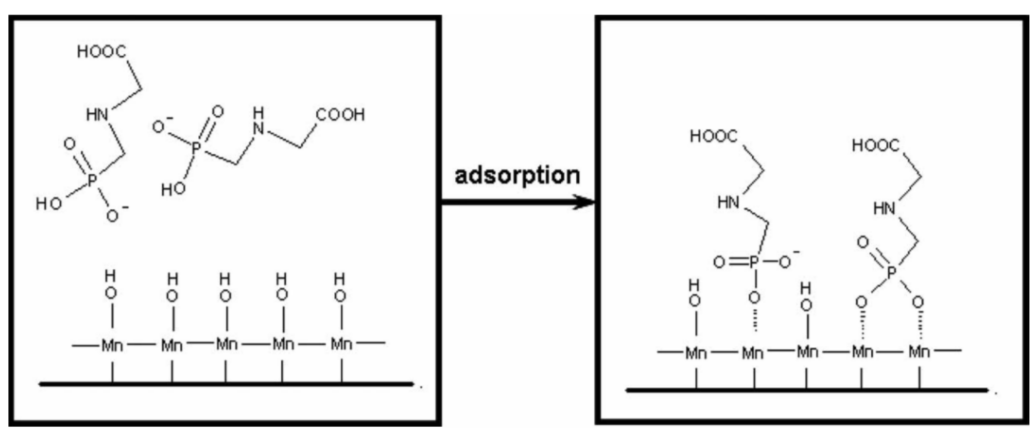

Figure 4. Kinetic of chemical adsorption on porous material [52].

With all the above-mentioned characteristics, polyphosphonates and polyphosphinopolymers have been widely and profusely used in oil and gas scale squeeze control due to their ease of adsorption, high scale inhibition efficiency, low economical cost, and relative environmental compatibility.

\subsubsection{Effect of Formation Variables in Adsorbing Characteristics of Polymer on Adsorbent}

Most reservoir sands and sandstones contain a given amount of clay. Clay particles are generally very small fractions of $\mu \mathrm{m}$ size range and contribute both to increasing the specific area of the core and to decreasing its permeability [53]. The specific area explains the high adsorbing capacity of clays toward scale inhibitors, whilst the permeability is expected to favor scale inhibitor reversible retention.

Research on uptake of nitrilotris methylene-phosphonic acid (NTMP) by kaolin, halloysite, and montmorillonite monitored by liquid phase ${ }^{31} \mathrm{P}$ NMR spectroscopy has ascertained that in the presence of $\mathrm{Ba}^{2+}$ or $\mathrm{Ca}^{2+}$, a significant increase of the amount of desorbed phosphorous was recorded. It was further maintained that a weak interaction between scale inhibitor and rock formation contributes to its release in contrast with a strong interaction between scale inhibitor and formation rock [54]. In another research to understand rock/phosphonate inhibitor interactions and effect of metal ions on scale inhibitor retention, it has been claimed that phosphonate precipitation increased, with major precipitation occurring near the front of the core upon inhibitor pill solution making contact with core material [55].

The effects of increased temperature and flow rate have been reported to cause higher equilibrium concentrations and faster dissolution kinetics for a diethylenetriamine pentamethylene phosphonic acid (DTPMP)/sandstone interaction study [24]. However, Dantas et al. [56] reported that the increase in temperature due to exothermic behavior of adsorption causes a decrease in adsorption capacity.

Zaitoun and Kohler [57] claimed that a change in $\mathrm{pH}$, temperature, brine composition, and polymer charge density can modify polymer adsorption characteristics on a given porous material. They further stressed that at a neutral $\mathrm{pH}$, the surface charge of natural sands and sandstones is negative, and thus, an increase in polymer anionicity raises charge repulsion with the rock and reduces the adsorption tendency. However, reports have shown that positive surface charge on $\mathrm{SiO}_{2}$ at a low $\mathrm{pH}$ based on the kinetics of dissolution could exist [58]. It has been reported that solution $\mathrm{pH}$ is the most important factor affecting the molar ratio of Ca to ATMP in a precipitation squeeze treatment with a marked increase 
in solution $\mathrm{pH}$, giving rise to an increase in the amount of Ca-ATMP precipitated [23]. Kosmulki [59] reported that the charges in various solid surfaces in aqueous solutions are dependent on the $\mathrm{pH}$. Furthermore, he maintained that in an aqueous solution of 1-1 electrolyte, the $\mathrm{pH}$-dependent charges on the solid surface govern the adsorption of ions.

\subsubsection{The Effect of Molecular Weight on Scale Inhibitor Adsorption}

Flood et al. [60] in their report stated that the strength of sodium polyacrylate (NaPA) scale inhibitor binding increases with its molecular weight. Adsorption of high molecular weight macromolecules has been reported to be largely irreversible, with significant desorption claimed to be observed only at shear rates exceeding $2000 \mathrm{~s}^{-1}$. The adsorption level according to the report then becomes directly dependent on the specific area of the rock, i.e., on its clay content [57]. Farooqui and Sorbie [13] maintained that the molecular weight of scale inhibitors is deemed to be one of the factors upon which both adsorption and precipitation processes depend on. They additionally asserted that the concentration of the polymer in the return curve of PPCA scale inhibitor used in their research was relative to the molecular weight distribution (MWD) effects and in its ability to prevent scale formation.

\subsubsection{Functional Group Reactivity/Pathways to Scale Inhibitor Adsorption on a Given Sand Surface}

Scale inhibitor molecules have a high tendency to adsorb on a given surface such as sand. Several pathways have been described for this. The first pathway is the linkage of one functional group to a mineral surface which provides a platform to the fixation of the whole macromolecule composed of several thousand monomer groups. The next pathway is reported to be where several weak linkages may produce a very strong attractive force [57]. This happens if electric repulsion forces between the polyanion and the mineral surface are not high and there exists moderate polymer charge density, minimal brine salinity, and neutral $\mathrm{pH}$. It has been reported that the main contribution to the binding energies comes from coulombic interaction, as the indication shows that coulomb interactions are favorable for the combination of scale inhibitors and calcite [42].

Most polymers used in enhanced oil recovery (EOR) applications are weakly anionic and, surprisingly, adsorb onto rocks with negative surface charge. The presence of local positive charges on clay edges [61] or the possibility of hydrogen bond formation with silica has been proposed to explain the high affinity of polymers for many reservoir rocks. However, Vazquez et al. [62] have reported that the cause of deposition of a solid or a gel-like immiscible liquid on the surface of a formation rock was because of the formation of a soluble inhibitor-cation complex or salt such as the inhibitor-Ca complex.

\subsubsection{Adsorption on Solid Surface}

The surface of quartzite sand consists of charged particles that produce field of force as depicted in Figure 5 below. The permanent negative charges on the quartzitic sand are charge balanced by cations exchangers which are chemically bound to the surfaces of the adsorbent. The interactions between these field of forces at the surface of sand and that from the molecule of the scale inhibitor to be adsorbed gives rise to surface adsorption on the sand surface [63]. The surface of sand consists of irregularities which are microscopic in nature and the existence of these irregularities give rise to variations in the magnitude of surface forces [64]. These surface forces play a significant role in the adsorption of scale inhibitors onto the sand surface. In contrast, Yan et al. [24]; Kan et al. [65] have reported from Tomson et al. [66] that the primary driving force for adsorption is not related to some specific inhibitor-surface interaction, rather to simple hydrophobic repulsion from the solution of macroneutral molecule of the calcium-inhibitor complex. 


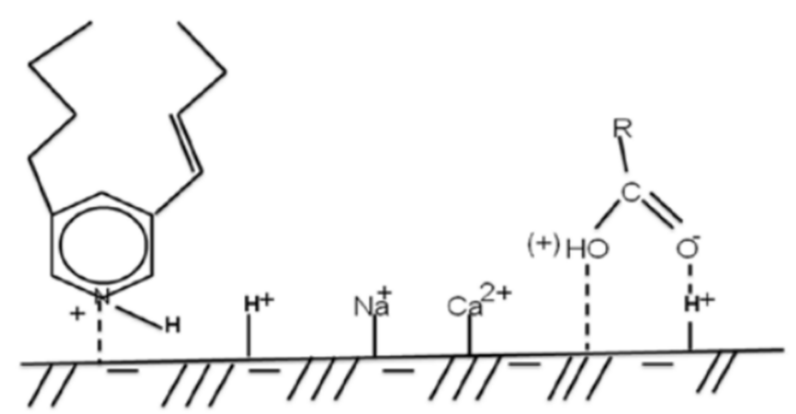

Figure 5. Active component ions on formation rock surface. Adapted from [63].

Two main forces of attraction synonymous with adsorption of scale inhibitor molecules onto the surface of sand are; physical and chemical forces. Physical forces give rise to physical adsorption while chemical forces give rise to chemical adsorption. Gupta and Bhattacharyya [67] described adsorption as one of the fascinating phenomena related to the behavior of fluids in a force field exerted by the solid surface. They maintained that a solid is a good adsorbent if the internal volume accessible to the adsorbate molecules or ions is high, and further stressed that a solid with large pore volume tend to also have a large area.

Sorbie et al. [68] outlined interactions between inhibitor and sand surfaces to involve three processes:

Normal adsorption/desorption;

Enhanced adsorption/desorption-which is sometimes designated as surface precipitation or surface condensation;

Precipitation or phase separation process itself.

A clear understanding of the properties of the adsorbent (sandstone) and the adsorbate contributes to a better mechanistic view of the inhibitor adsorption/desorption behavior. Most reservoir rocks, when brought into contact with water, develop positively charged edges [61] and become negatively charged at higher $\mathrm{pH}[63,69]$. The negative surface charge on quartz (the principal component of sandstone), when immersed in water or at normal $\mathrm{pH}$, is generated by dissociation or de-protonation of the weakly acidic surface hydroxyl groups, silanols [70] as follows:

$$
\mathrm{SiO}-\mathrm{H}+\mathrm{H}_{2} \mathrm{O} \rightarrow \mathrm{SiO}^{-}+\mathrm{H}_{3} \mathrm{O}^{+}
$$

Ibrahim et al. [25] reported that the surface of quartzitic or siliceous sand has an isoelectric point (or alternatively, a point of zero charge) at a $\mathrm{pH}$ of about 2, above which the concentration of negative charge on the surface increases. They reported that at intermediate $\mathrm{pH}$ values (approximately 4) and at room temperature, the adsorption of inhibitor was found to be lower than at both $\mathrm{pH} 2$ and $\mathrm{pH} 6$ due to a relative weakening of both the hydrogen bonding and calcium binding mechanism. Adsorption is thought to occur through an electrostatic attraction or physical adsorption between the inhibitor and formation mineral [68].

There has been indication that surface area, particularly the internal pore surface and pore size distribution and the nature of pores, determine the extent of adsorption [71]. The physical size and form of the solid particles, the chemistry of the adsorbent, namely, degree of ionization at the surface, the types of functional groups present, and the degree to which these properties change in contact with an aqueous solution are important considerations in determining the adsorption capacity of a solid [67].

Oluyemi [16] reported that adsorption and desorption characteristic of formation in unconsolidated reservoir rocks may be affected by grain-size distribution, porosity and permeability, and eroding effects of particles of sand in motion. Oluyemi further ascertained that the eroding effects of sand particles can cause a reduction in the amount of inhibitors adsorbed as a result of reduction of the surface area of sand available for 
adsorption or the stripping off of the already adsorbed inhibitor species from the formation. Similarly, McMahon et al. [31] in their laboratory tests simulating field conditions showed there can be a possible reduction in the concentration of inhibitor available to protect steel surfaces. They maintained that large amounts of corrosion inhibitors can be lost from bulk solution by adsorption onto the surface of produced sand grains.

\subsubsection{Chemical Adsorption of Scale Inhibitors onto Sand Surface}

Chemisorption on sand surface consists essentially of the formation of a chemical compound at the surface of sand and involves an exchange of or sharing of electrons between the adsorbate molecules and the adsorbent. The surface of the adsorbent consists of active functional groups which take part in chemical interactions thereby producing effects that are less reversible and different from that of physical adsorption [71]. Zhang and Somasundaran [64] in their report claimed that there was a sharp increase in the adsorption of calcium on quartzitic surfaces, and they attributed the increase to chemisorption caused by hydrolyzed calcium ions. Chemical reactions for the process of adsorption and desorption due to enthalpy and entropy change are given below [72]:

$$
\begin{gathered}
\text { Clay- } \mathrm{Ca}^{2+}+\mathrm{H}_{2} \mathrm{O} \text { Clay- } \mathrm{H}^{+}+\mathrm{OH}^{-}+\mathrm{Ca}^{2+}+\text { Heat } \\
\text { Clay- } \mathrm{R}_{3} \mathrm{NH}^{+}+\mathrm{OH}^{-} \text {Clay }+\mathrm{R}_{3} \mathrm{~N}:+\mathrm{H}_{2} \mathrm{O} \\
\text { Clay-RCOOH }+\mathrm{OH}^{-} \mathrm{Clay}+\mathrm{RCOO}^{-}+\mathrm{H}_{2} \mathrm{O}
\end{gathered}
$$

The desorption of $\mathrm{Ca}^{2+}$ from the clay surface and the adsorption of the $\mathrm{H}^{+}$onto the negative site of clay in Equation (2) gave rise to increased $\mathrm{pH}$ and, additionally, an exothermic process. The displacement of $\mathrm{Ca}^{2+}$ from the solid surface and replacement with $\mathrm{H}^{+}$paves the way for adsorption reaction of ionized chemical inhibitor as seen in Equation (3). Change in $\mathrm{pH}$ which could result from brine flooding tends to alter the reaction kinetics, thereby causing release or desorption of the inhibitor into the flowing stream for further reaction with $\mathrm{Ca}^{2+}$ or any other cation present in seawater used for flooding. For many reservoir rocks, there exists a high affinity for chemical inhibitors due to the presence of hydrogen bonding, electrostatic attraction, and hydrophobic repulsion from macro neutral molecules [24]. The high affinity of these chemicals with weakly anionic groups adsorbs onto rocks with negative surface charge and as such cause local positive charges on clay edges [61].

\subsubsection{Physical Adsorption of Scale Inhibitors onto Sand Surface}

Physical adsorption or electrostatic adsorption between the inhibitor and formation minerals has been reported to be the cause of adsorption [68]. Dang et al. [73] have reported that physical adsorption occurs when polymer molecules are adsorbed onto rock surface by virtue of a lower overall free energy. They further explained that entropic contribution whereby the liberation of water molecules previously bound to the rock surface or to the polymer due to lower free energy causes an increase in entropy.

Veloso et al. [17] in their report have claimed that capacity adsorption in physisorption decreases with increasing temperature. They further reported a $7 \%$ increase in adsorption capacity obtained from their experimental data after temperature increase from 30 to $80^{\circ} \mathrm{C}$. They suggested that electrostatic interactions or changes in the rock surface could have occurred to facilitate interaction between the rock and inhibitor.

\section{Adsorption through Hydrogen Bonding Mechanism}

Dellostritto et al. [74] have ascertained that the understanding of the structure of the Hbond network at the quartz-water interface is vital for a complete analysis of the behavior of the system. They additionally claimed that the surface charging of quartz is highly dependent on ion concentration as well as cation species with cations promoting negative surface charge as a function of $\mathrm{pH}$. It has been reported that surfactants with carboxylic, phenolic, hydroxyl, and amine groups form hydrogen bond with solid surfaces species. The 
bond formed between the surfactant functional groups and the mineral surfaces is reported to be stronger than that formed between the mineral and interfacial water molecules for adsorption due to hydrogen bonding to take place [64].

\subsubsection{Adsorption Isotherm}

There exists a relationship between the type of isotherm and the nature of the adsorbent. The pore size distribution of the adsorbent is a function of the type of isotherm obtained for a given adsorbate. At equilibrium, the concentration of the solute or adsorbate in the bulk liquid to the concentration of the adsorbate on the solid phase defines the adsorption isotherm [20].

It has been reported that in adsorption/desorption squeeze treatment applications, the nature of the isotherm depicts the behavior of the inhibitor return profile [75]. Reports have depicted that the nature of adsorption isotherm is influenced by (i) inhibitor species itself, (ii) the formation brine composition and $\mathrm{pH}$, (iii) application $\mathrm{pH}$ and temperature, and (iv) the nature of adsorbing surface, i.e., surface charge, reservoir mineralogy, and wettability [62,75]. Bassioni [76] maintained that electrostatic interaction by means of ionpair formation, ion exchange, hydrogen bonding, or complex formation on the surface of formation rock with saturated adsorption plateau gives rise to adsorption. Bassioni further stressed that anion-anion interaction such as competitive adsorption of organic (citrate) and inorganic (sodium chloride, nitrate, carbonate or sulphate) on a positively charged surface may lead to formation of a second layer as well cause increased adsorbent concentration. The reason given was a reduction of the adsorption enthalpy and consequent increase of the system's entropy.

Boels et al. [77] maintained that the presence of calcium during adsorption process causes a transformation in the equilibrium adsorption isotherm from Langmuir to Freundlich type with much adsorption capabilities. They further claimed that calcium increases the rate of adsorption. Langmuir model was originally developed to describe gas adsorption onto activated carbon based on the assumptions that (i) the adsorbent surface has energetically uniform sites for adsorbate ions, atoms, and molecules, (ii) no adsorbate-adsorbate interactions are present, (iii) the same mechanism is followed throughout the process, and (iv) at the maximum adsorption, the surface is covered with only a monolayer [67].

\subsection{Theory and Techniques}

There are two methods by which oil field scale inhibitors are administered into oil wells. These two methods are continuous injection and squeeze or batch injection. Continuous injection, as the name implies, involves the continuous injection of chemical inhibitors into the oil well system by means of electric pumps or gas-driven chemical pumps. This method is used for prevention of scales in areas such as top sides, chokes, valves and production tubings where squeezing is not possible. Other well/reservoir enhancement or treatment chemicals such corrosion inhibitors, hydrate and wax inhibitors, as well as seawater, can also be applied through continuous injection [78]. Li et al. [79] in their experimental study on the kinetic behavior of natural gas hydrate reported that continuous seawater injection can keep the balance between productivity and sand production through controlling production pressure. Alternatively, squeeze treatment is viewed as the most technically favorable and economically viable option for scale treatment in both conventional and subsea oilfields. Squeeze or batch treatment is applied as a one-off treatment designed to inject scale inhibitor into the near wellbore region accompanied by brine overflush which is injected to drive the scale inhibitor further into the formation. Upon shut-in, to allow the scale inhibitor to adequately adsorb onto the formation fabric over a period, the production of the well is put back into operation. The diagram in Figure 6 below shows a schematic field application of the squeeze procedure applied in the laboratory. 


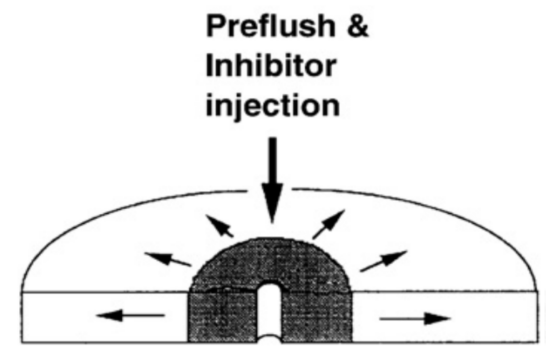

Sea Water Overflush

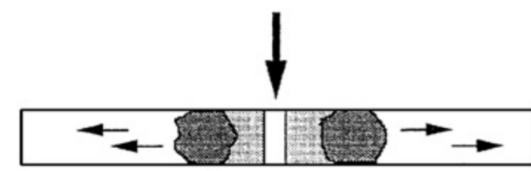

Shut in

Back production

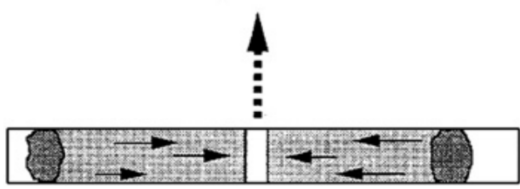

Figure 6. Schematic view of scale treatment procedure [78].

The laboratory sand pack core holding assembly method using a bench top assembly is shown schematically in Figure 7 below and is used to evaluate the adsorption rate, the adsorption amount, and rate of desorption of the chemical inhibitors.

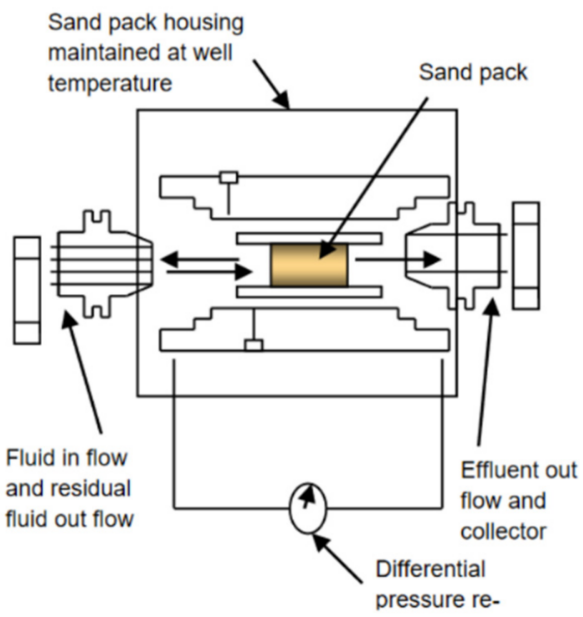

Figure 7. Schematic diagram of sand pack/core holding assembly for Sand pack test. Extracted and modified from [14].

This technique involves packing of pre-weighed crushed core samples or a sand pack into a core holder assembly. Synthetic seawater (SSW) is flooded into the sample at a controlled rate to condition the sand pack and observe the permeability of the SSW into the crushed or sand pack sample. This would be the initial preflush test. Afterwards, synthetic seawater dosed with predetermined concentration of the scale inhibitor is injected into the crushed core sample or sand pack at a determined rate of flow until the inhibitor concentration of the effluent reaches the maximum initial concentration of the injected. The effluent inhibitor solution is collected at intervals of time and the residual concentration analyzed [24] to ascertain maximum inhibitor saturation, as well as rate of adsorption, and the setup is shut in, while maintaining the initial heated test temperature, and allowed 
to remain over a period of about $24 \mathrm{~h}$ to achieve maximum adsorption onto the crushed specimen or sample.

At the end of the 24-h shut-in, the crushed sand pack sample is flooded with synthetic formation water (SFW) at an also determined flow rate of, for example, $5 \mathrm{~mL} / \mathrm{h}$, and the effluent collected at intervals of about $1 \mathrm{~h}$. The concentration of the desorbed inhibitor in the collected effluent portions is analyzed using ICP-OES [24].

\section{Conclusions}

The mechanism underpinning precise retention of inhibitors and their performance in sand-producing reservoirs is not well published, and it is difficult to understand. Therefore, this gap in knowledge requires concerted research. We therefore recommend addressing the gap in knowledge using experimental and numerical methods. The experimental method involves engineered sand-pack flooding investigation process with polyphosphonate and polyphosphinopolymer scale inhibitors, lab-based brine and low salinity aqueous water, and validation of lab results with the numerical method.

Funding: This research received no external funding.

Data Availability Statement: Not applicable.

Conflicts of Interest: The authors declare no conflict of interest.

\section{References}

1. Mahmuda, H.B.; Leonga, V.H.; Lestariono, Y. Sand production: A smart control framework for risk mitigation. Petroleum 2020, 6 , 1-13. [CrossRef]

2. Vincent, O.N.; Abiola, S.O.; Felix, O.O.; Ajienk, J.A. Sanding in Oil Well Reservoir Completions. In Proceedings of the Nigeria Annual International Conference and Exhibition, Lagos, Nigeria, 6-8 August 2012.

3. Cook, J.M.; Bradford, I.D.R.; Plumb, R.A. A Study of the Physical Mechanisms of Sanding and Application to Sand Production Prediction. In Proceedings of the European Petroleum Conference, London, UK, 25 October 1994.

4. Shafiq, M.U.; Mahmud, H.B. Sandstone matrix acidizing knowledge and future development. J. Petrol. Explor. Prod. Technol. 2017, 7, 1205-1216. [CrossRef]

5. Salahi, A.; Dehghan, A.N.; Sheikhzakariaee, S.J. Sand production control mechanisms during oil well production and construction. Pet. Res. 2021, in press.

6. Shchukin, E.D. The influence of Surface-Active Media on the Mechanical Properties of Materials. Adv. Colloid Interface Sci. 2006, 123-126, 33-34. [CrossRef] [PubMed]

7. Traskin, V.Y. Rehbinder Effect in Tectonophysics. Izv. Phys. Solid Earth 2009, 45, 952-963. [CrossRef]

8. Prempeh, K.O.K.; Chequer, L.; Badalyan, A.; Bedrikovetsky, P. Effects of the Capillary-Entrapped Phase on Fines migration in Porous Media. J. Nat. Gas Sci. Eng. 2020, 73, 103047. [CrossRef]

9. Merdhah, A.B.B.; Yassin, A.A.M. Study of Scale Formation in Oil Reservoir during Water Formation Injection-A review. Mar. Sci. Technol. Semin. 2007, 2047, 1-7.

10. Hasson, D.; Shemer, H.; Sher, A. State of the Art of Friendly "Green" Scale Control Inhibitors: A Review Article. Ind. Eng. Chem. Res. 2011, 50, 7601-7607. [CrossRef]

11. Voloshin, I.A.; Ragulin, V.V.; Yabayeva, E.N.; Diakonov, L.I.; Mackay, J.E. Scaling Problems in Western Siberia. In Proceedings of the SPE fifth International Symposium on Oilfield Scale, Aberdeen, UK, 29-30 January 2003; p. 1-8.

12. Jordan, M.M.; Johnston, C.J.; Sutherland, L. Impact of Reservoir Temperature on Scale Inhibitor Retention-The Challenge of Ultra-Low Temperature Sandstone Reservoirs. In Proceedings of the SPE International Oilfield Scale Conference and Exhibition, Aberdeen, UK, 11-12 May 2016.

13. Farooqui, N.M.; Sorbie, K.S. The Use of PPCA in Scale-Inhibitor Precipitation Squeezes: Solubility, Inhibition Efficiency, and Molecular-Weight Effects. Society of Petroleum Engineers. In Proceedings of the SPE International Oilfield Scale Conference and Exhibition, Aberdeen, UK, 14-15 May 2014.

14. Stamatakis, E.; Chatzichristos, C.; Sagen, J.; Stubos, A.K.; Palyvos, I.; Muller, J.; Stokkan, J.-A. An Integrated Radiotracer Approach for the Laboratory Evaluation of Scale Inhibitors Performance in Geological Environments. Chem. Eng. Sci. 2006, 61, 7057-7067. [CrossRef]

15. Andrei, M.; Malandrino, A. Comparative Coreflood Studies for Precipitation and Adsorption Squeeze with PPCA as the Scales Inhibitor. Pet. Sci. Technol. 2003, 21, 1295-1315. [CrossRef]

16. Oluyemi, G.F. Chemical Inhibitor Adsorption and Desorption Characteristics of Common Gravel Pack Sands under Static and Dynamic Conditions. Spec. Top. Rev. Porous Media Int. J. 2013, 4, 159-169. [CrossRef]

17. Veloso, C.B.; Silva, A.N.A.; Watanabe, T.T.T.G.; Paes, J.F.B.C.; De Luna, F.M.T.; Cavalcante, C.L., Jr. Scale Inhibitor Adsorption Studies in Rock Sandstone Type. Adsorption 2014, 20, 977-985. [CrossRef] 
18. Bezemer, C.; Bauer, K.A. Prevention of Carbonate Scale Deposition: A Well-Packing Technique with Controlled Solubility Phosphates. J. Pet. Technol. 1969, 21, 505-514. [CrossRef]

19. Liu, B.; Zeng, L.; Mao, J.; Ren, Q. Simulation of Levulinic Acid Adsorption in Packed Beds Using Parallel Pore/Surface Diffusion Model. Chem Eng. Technol. 2010, 33, 1146-1152. [CrossRef]

20. Selvaraju, N.; Pushpavanam, S. Adsorption Characteristics on Sand and Brick Beds. Chem. Eng. J. 2009, 147, 130-138. [CrossRef]

21. Garmeh, G.; Johns, R.T.; Lake, L.W. Pore-Scale Simulation of Dispersion in Porous Media. In Proceedings of the SPE Annual Technical Conference and Exhibition, Anaheim, CA, USA, 11-14 November 2009; pp. 559-567.

22. Kahrwad, M.; Sorbie, K.S.; Boak, L.S. Coupled Adoption/Precipitation of Scale Inhibitors; Experimental Results and Modelling. In Proceedings of the SPE International Oilfield Scale Conference, Aberdeen, UK, 28-29 May 2008.

23. Tantayakom, V.; Fogler, H.S.; Chavadej, S. Study of Scale Inhibitor Reactions in Precipitation Squeeze Treatments. In Proceedings of the 2005 SPE International Symposium on Oilfield Chemistry, Houston, TX, USA, 2-4 February 2005. SPE 92771.

24. Yan, F.; Zang, F.; Bhandari, N.; Liu, Y.; Wang, L.; Dai, Z.; Zhang, Z.; Bolanos, V.; Kan, A.; Tomson, M. Interaction between Scale Inhibitors and Shale and Sandstone Formations. Society of Petroleum Engineers. In Proceedings of the SPE International Symposium on Oilfield Chemistry, The Woodlands, TX, USA, 13-15 April 2015.

25. Ibrahim, J.; Sorbie, K.S.; Boak, L.S. Coupled Adsorption/Precipitation Experiments: 2. In In Non-Equilibrium Sand Pack Treatments. In Proceedings of the SPE International Conference on Oilfield Scale, Aberdeen, UK, 30-31 May 2012.

26. Sorbie, K.S.; Gdanski, R.D. A Complete Theory of Scale-Inhibitor transport and Adsorption/Desorption in Squeeze treatments. In Proceedings of the SPE International Symposium on Oilfield Scale, Aberdeen, UK, 11-12 May 2005.

27. Jordan, M.M.; Sorbie, K.S.; Griffin, P.; Hennessey, S.; Hourston, K.E.; Waterhouse, P. Scale Inhibitor Adsorption/Desorption vs Precipitation: The Potential for Extending Squeeze Life While Minimising Formation Damage. In Proceedings of the European Formation Damage Conference, Hague, The Netherlands, 15-16 May 1995.

28. Brown, J.M.; Shen, D.; Satya Gupta, D.V.; Taylor, G.; Self, R.W. Laboratory and Field Studies of Long-Term Release Rates for a Solid Scale. In Proceedings of the SPE International Symposium on Oilfield Chemistry, Woodlands, TX, USA, 11-13 April 2011.

29. Oyeneyin, B. Integrated Sand Management for Effective Hydrocarbon Flow Assurance. In Development in Petroleum Science, 1st ed.; Dennis, S., Ed.; Elsevier: Amsterdam, The Netherlands, 2015; Volume 63, pp. 129-138.

30. Berntsen, A.N. Scale Effect in Volumetric Sand Production. American Rock Mechanics Association. In Proceedings of the 46th US Rock Mechanics/Geomechanics Symposium, Chicago, IL, USA, 24-27 June 2012.

31. Mcmahon, A.J.; Martin, J.W.; Harris, L. Effects of Sand and Interfacial Adsorption Loss on Corrosion Inhibitor Efficiency. In Proceedings of the NACE International-Corrosion 2005, Houston, TX, USA, 3-7 April 2005; pp. 1-23.

32. Molnes, S.N.; Torrijos, I.P.; Strand, S.; Paso, K.G.; Syverud, K. Sandstone Injectivity and Salt Stability of Cellulose Nanocrystals (CNC) Dispersions-Premises for use of CNC in Enhanced Oil Recovery. Ind. Crop. Prod. 2016, 93, 152-160. [CrossRef]

33. Cai, L.; Tong, M.; Wang, X.; Kim, H. Influence of Clay Particles on the Transport and Retention of Titanium Dioxide Nanoparticles in Quartz Sand. Environ. Sci. Technol. 2014, 48, 7323-7332. [CrossRef]

34. Tusher, K.S.; Mehajan, S.P.; Khilar, K.C. Colloid-Associated Contaminant Transport in Porous Media: 1. Experimental Studies. AIChE J. 2002, 48, 2366-2374.

35. Nisrine, S.; Azita, A.S.; Aziz, O.; Henri, B. Numerical Simulation of Retention and Release of Colloids in Porous Media at the Pore Scale. Colloids Surf. A Physicochem. Eng. Asp. 2013, 427, 33-40.

36. Abadzic, D.S.; Ryan, N.J. Particle Release and Permeability Reduction in a Natural Zeolite (clinoptilolite) and Sand porous Medium. Environ. Sci. Technol. 2001, 35, 4502-4508. [CrossRef]

37. Wang, S.; Chung, K.H.; Masliyah, J.H.; Gray, M.R. Deposition of Fine Particles in Packed Beds at Hydrotreating Conditions: Role of Surface Chemistry. Ind. Eng. Chem. Res. 1999, 38, 4878-4888. [CrossRef]

38. Fielder, G.D. Scale Inhibitor Selection for a High Suspended Solids Produced Water Systems. In Proceedings of the International Conference on Corrosion, Houston, TX, USA, 26 March 2000.

39. Chakraborty, A.; Saha, B.B.; Aristov, Y.I. Dynamic Behaviours of Adsorption Chiller: Effects of the Silica Gel Grain Size and Layers. Energy 2014, 78, 304-312. [CrossRef]

40. Wuyep, E.O.; Oluyemi, G.F.; Yates, K.; Akinsanya, A.R. Evaluation of Interaction between Oilfield Chemicals and Reservoir Rocks. Nat. Resour. Res. 2019, 29, 1239-1258. [CrossRef]

41. Ghosh, B.; Kundu, S.; Senthilmurugan, B. A New Squeeze Scale Inhibitor for a Sandstone Reservoir with a Stimulation Effect. Pet. Sci. Technol. 2012, 30, 402-411. [CrossRef]

42. Zeng, J.-P.; Wang, F.-H.; Gong, S.-D. Molecular Dynamics Simulation of the Interaction between Polyaspartic Acid and Calcium Carbonate. Mol. Simul. 2013, 39, 169-175. [CrossRef]

43. Kelland, M.A. Production Chemicals for the Oil and Gas Industry; CRC Press: Boca Raton, FL, USA, 2009 ; pp. 53-91.

44. Fleming, N.; Bourne, H.M.; Strachan, C.J.; Buckley, A.S. Development of an Ecofriendly Scale Inhibitor for Harsh Scaling Environments. In Proceedings of the SPE International Symposium on Oilfield Chemistry, Houston, TX, USA, 13-16 February 2001.

45. Ketrane, R.; Saidani, B.; Gil, O.; Leleyter, L.; Baraud, F. Efficiency of Five Scale Inhibitors on Calcium Carbonate Precipitation from Hard Water: Effect of Temperature and Concentration. Desalination 2009, 249, 1397-1404. [CrossRef]

46. Jonasson, R.G.; Rispler, K.; Wiwchar, B.; Gunter, W.D. Effect of Phosphonate Inhibitors on Calcite Nucleation kinetics as a Function of Temperature using Light Scattering in an Autoclave. Chem. Geol. 1996, 132, 215-225. [CrossRef] 
47. Li, F.; Wu, W.; Li, R.; Fu, X. Adsorption of Phosphate by Acid-Modified Fly Ash and Palygorskite in Aqueous Solution: Experimental and Modeling. Appl. Clay Sci. 2016, 132-133, 343-352. [CrossRef]

48. Wylde, J.J. Scale Inhibition Application in Northern Alberta: A Case History of an Ultra-High Temperature Scale Inhibition Solution in Fire Tube Heaters. In Proceedings of the SPE International Conference on Oilfield Scale, Aberdeen, UK, 26-27 May 2010.

49. Kumar, T.; Vishwanatham, S.; Kundu, S.S. A Laboratory Study on Pteroyl-1-Glutamic Acid as a Scale Prevention Inhibitor of Calcium Carbonate in Aqueous Solution of Synthetic Produced Water. J. Pet. Sci. Eng. 2010, 71, 1-7. [CrossRef]

50. Jones, F.; Stanley, A.; Oliveira, A.; Rohl, A.L.; Reyhani, M.M.; Parkinson, G.M.; Ogden, M.I. The Role of Phosphonate Speciation on the Inhibition of Barium Sulfate Precipitation. J. Cryst. Growth 2003, 249, 584-593. [CrossRef]

51. Yang, Q.; Liu, Y.; Gu, A.; Ding, J.; Shen, Z. Investigation of Calcium Carbonate Scaling Inhibition and Scale Morphology by AFM. J. Colloid Interface Sci. 2001, 240, 608-621. [CrossRef]

52. Hao, C.; Qin, L.; Yan, Q.; Qiu, Z.; Jianping, Z. Preparation and Adsorption Performance of $\mathrm{MnO}_{2} / \mathrm{PAC}_{\text {Composite towards }}$ Aqueous Glyphosate. Environ. Technol. 2012, 33, 2049-2056.

53. Saldungaray, P.M.; Caretta, F.; Sofyan, M. Formation Fines Stabilization using Surface Adsorption Polymerization: Field Application of an Emerging Technology. In Proceedings of the SPE Asia Pacific Oil and Gas Conference and Exhibition, Jakarta, Indonesia, 17-19 April 2001.

54. Jordana, R.; Howe, R.F.; Guan, H. Retention and Release of Scale Inhibitors in Different Clay Minerals. In Proceedings of the SPE International Conference and Exhibition on Oilfield Scale, Aberdeen, UK, 30-31 May 2012.

55. Mason, B.T.; Kan, A.T.; Fu, G.; Shen, D.; El Din, H.A.N.; Al-Saaaiari, H.; Al Thubaiti, M. Mechanistic Understanding of Rock/Phosphonate Interactions and the Effect of Metal Ions on Inhibitor Retention. In Proceedings of the 2006 SPE International Symposium on Oilfield Scale, Aberdeen, UK, 31 May-1 June 2008; pp. 325-336.

56. Dantas, T.L.P.; Luna, F.M.T.; Silva, I.J., Jr.; De Azevedo, D.C.S.; Grande, C.A.; Rodrigues, A.E.; Moreira, R.F.P.M. Modelling of the Fixed-Bed Adsorption of Carbon Dioxide and a Carbon Dioxide-Nitrogen Mixture on Zeolite 13X. Braz. J. Chem. Eng. 2011, 28, 533-544. [CrossRef]

57. Zaitoun, A.; Kohler, N. The Role of Adsorption in Polymer Propagation through Reservoir Rocks. In Proceedings of the SPE International Symposium on Oilfield Chemistry, San Antonio, TX, USA, 4-6 February 1987.

58. Kosmulski, M. pH-Dependent Surface Charging and Points of Zero Charge: III. Update. J. Colloid Interface Sci. 2006, $298,730-741$. [CrossRef]

59. Kosmulski, M. The pH-Dependent Surface Charging and Points of Zero Charge: V. Update. J. Colloid Interface Sci. 2011, 353, 1-15. [CrossRef]

60. Flood, C.; Cosgrove, T.; Espidel, Y.; Howell, I.; Revel, P. Sodium Polyacrylate Adsorption onto Anionic and Cationic Silica in the Presence of Salts. Langmuir 2007, 23, 6191-6197. [CrossRef]

61. Alotaibi, M.B.; Azmy, R.; El Din, H.A.N. A Comprehensive EOR Study Using Low Salinity Water in Sandstone Reservoirs. In Proceedings of the SPE Improved Oil Recovery Symposium, Tulsa, OK, USA, 24-28 April 2010.

62. Vazquez, O.; Thanasutives, P.; Eliasson, C.; Fleming, N.; Mackay, E. Modelling the Application of Scale-Inhibitor-Squeeze Retention-Enhancing Additives. SPE Prod. Oper. 2011, 26, 270-277.

63. Strand, S.; Puntervold, T.; Austad, T. Water Based EOR from Clastic Oil Reservoirs by Wettability Alteration: A review of chemical aspects. J. Pet. Sci. Eng. 2016, 146, 1079-1091. [CrossRef]

64. Zhang, R.; Somasundaran, P. Advances in adsorption of surfactants and their mixtures at solid/solution interfaces. Adv. Colloid Interface Sci. 2006, 123-126, 213-229. [CrossRef]

65. Kan, A.T.; Fu, G.; Tomson, M.B.; Al-Thubaiti, M.; Xiao, A.J. Factors Affecting Scale Inhibitor Retention in Carbonate-Rich Formation during Squeeze Treatment. SPE J. 2004, 9, 280-289. [CrossRef]

66. Tomson, M.B.; Fu, G.; Watson, M.A.; Kan, A.T. Mechanisms of Mineral Scale Inhibition. SPE Prod. Facil. 2003, 192-199. [CrossRef]

67. Gupta, S.S.; Bhattacharyya, K.G. Adsorption of Metal Ions by Clays and Inorganic Solids. RSC Adv. 2014, 4, 28537-28586. [CrossRef]

68. Sorbie, K.S.; Yuan, M.D.; Chen, P.; Todd, A.C.; Wat, R.M.S. The Effect of pH, Calcium, and Temperature on the Adsorption of Phosphonate Inhibitor onto Consolidated and Crushed Sandstone. In Proceedings of the 68th Annual Technical Conference and Exhibition of the SPE, Houston, TX, USA, 3-4 October 1993.

69. Dove, P.M.; Craven, C.M. Surface charge density on silica in alkali and alkaline earth chloride electrolyte solutions. Geochim. Cosmochim. Acta 2005, 69, 4963-4970. [CrossRef]

70. Buyuktimkin, T.; Wurster, D.E. The Influence of the Adsorption of Metoclopramide on the Surface Ionization of Fumed Silica. Int. J. Pharm. 2015, 478, 164-171. [CrossRef]

71. Gupta, S.S.; Bhattacharyya, K.G. Kinetics of Adsorption of Metal Ions on Inorganic Materials: A review. Adv. Colloid Interface Sci. 2011, 162, 39-58. [CrossRef]

72. Ivan, D.; Pinerez, T.; Austad, T.; Strand, S.; Puntervoid, T.; Wrobel, S. Linking Low Salinity EOR Effects in Sandstone to pH, Mineral Properties and Water Composition. In Proceedings of the SPE Improved Oil Recovery Conference, Tulsa, OK, USA, 11-13 April 2016; pp. 1-17.

73. Dang, T.Q.C.; Chen, Z.; Nguyen, T.B.N.; Bae, W. Investigation of Isotherm Polymer Adsorption in Porous Media. Pet. Sci. Technol. 2014, 32, 1626-1640. [CrossRef] 
74. Dellostritto, M.J.; Kubicki, J.D.; Sofo, J.O. Effect of Ions on H-Bond Structure and Dynamics at the Quartz (101)-Water Interface. Langmuir 2016, 32, 11353-11365. [CrossRef]

75. Jordan, M.M.; Sorbie, K.S.; Jiang, P.; Yuan, M.D.; Todd, A.C.; Taylor, K.; Hourston, K.E.; Ramstad, K. Mineralogical Control on Inhibitor Adsorption/Desorption in Brent Group Sandstone and their Importance in Predicting and Extending Field Squeeze Lifetimes. In Proceedings of the European Production Operations Conference and Exhibition, Aberdeen, UK, 15-17 March 1994

76. Bassioni, G. Mechanistic aspects on the influence of inorganic anion adsorption on oilfield scale inhibition by citrate. J. Pet. Sci. Eng. 2010, 70, 298-301. [CrossRef]

77. Boels, L.; Keesman, K.J.; Witkamp, G. Adsorption of Phosphonate Antiscalant from Reverse Osmosis Membrane Concentrate onto Granular Ferric Hydroxide. Environ. Sci. Technol. 2012, 46, 9638-9645. [CrossRef]

78. Baraka-Lokmane, S.; Sorbie, K. Effect of $\mathrm{pH}$ and scale inhibitor concentration on phosphonate-carbonate interaction. J. Pet. Sci. Eng. 2010, 70, 10-27. [CrossRef]

79. Li, D.; Ren, S.; Xu, Y.; Rui, H. Experimental Study on Kinetic Behaviors of Natural Gas Hydrate Production via Continuous Simulated seawater Injection. Energy Fuels 2019, 33, 8222-8230. [CrossRef] 